\title{
Conflitos no Mar do Sul da China: o que o Brasil tem a ver com isso? Leticia Cordeiro Simões de Moraes Lima
}

Vínculo Institucional: Doutoranda em Relações Internacionais do PPGRI-UERJ e professora do curso de Relações Internacionais do Unilasalle-RJ.

\section{Resumo:}

As disputas territoriais no Mar do Sul da China (MSC) vêm despertando a atenção ao redor do globo. Contudo, tais questões passaram a receber maior atenção devido à elevação das tensões entre China e EUA naquela região. No Brasil, há pouco destaque e pouca informação sobre os principais atores envolvidos e quais as consequências do início de um conflito entre duas grandes potências na Ásia-Pacífico. Apesar de estar no imaginário do brasileiro de que se trata do 'outro lado do mundo' e que o impacto de um possível embate naquelas águas seria muito pequeno para o país, não poderíamos estar mais equivocados. Por que o Brasil deve se preocupar, mas também se informar sobre um conflito no MSC? Este artigo pretende apresentar em linhas gerais um panorama dos lados do conflito e as razões para o Brasil ser um dos primeiros afetados por uma hipotética crise lá.

\section{Palavras-chaves:}

Mar do Sul da China; Brasil; Conflitos.

\section{Abstract:}

Territorial disputes in the South China Sea (SCS) have been raising attention around the globe. However, these issues came to receive more attention due to the increasing tensions between China and the US in that region. In Brazil, there is little prominence and information about the main actors involved and what the consequences of the beginning of a conflict between two major powers in Asia Pacific. Despite being in the imagination of Brazilian people that it is the 'other side of the world' and that the impact of a possible clash in those waters would be very small for the country, we could not be more wrong. Why should Brazil care about a conflict in the SCS? This article intends to outline an overview of the sides of the conflict and 


\section{NEIBA}

VOLUME VII

Dossiê: SimpoRI 2018

the reasons why Brazil is one of the first to be affected by a hypothetical crisis in the SCS.

Keywords:

South China Sea; Brazil; Conflicts. 


\section{NEİBA}

\section{Introdução}

As disputas territoriais no Mar do Sul da China (MSC) vêm despertando a atenção de políticos e estudiosos ao redor do globo, apesar de ter pouco destaque na academia e nos veículos de notícias brasileiros. Contudo, tais questões passaram a receber maior atenção, em grande medida, devido à elevação das tensões entre China e EUA naquela região, com a construção de ilhas artificiais, a passagem de embarcações e aeronaves em áreas contestadas e as disputas territoriais pelos países que circundam o mar.

Tais disputas territoriais têm questões muito mais profundas que um possível embate entre duas superpotências, são consequência de conflitos e negociações regionais entre a China e os demais países periféricos banhados pelo MSC, como Filipinas, Vietnã, Malásia, Indonésia e Brunei. Um possível escalonamento do conflito entre os Estados chinês e americano na região do MSC (ZHIYUE, 2015), refletiria diretamente no posicionamento militar e de segurança regional das partes envolvidas, no comércio marítimo internacional e no posicionamento dos países membros da Associação de Países do Sudeste Asiático (ASEAN) ${ }^{1}$ que estão intimamente ligados à disputa.

No Brasil, há pouco destaque e pouca informação sobre os principais atores envolvidos, suas motivações e quais as consequências do início de um conflito entre duas grandes potências na Ásia-Pacífico. Apesar de estar no imaginário do brasileiro de que se trata do 'outro lado do mundo' e que o impacto de um possível embate naquelas águas seria muito pequeno para o país, não poderíamos estar mais equivocados.

Por que o Brasil deve se preocupar, mas também se informar sobre um conflito no MSC? Este

\footnotetext{
1 São países membros da ASEAN: Tailândia, Indonésia, Filipinas, Malásia, Cingapura (conhecidos como membros fundadores da Associação em 1967), Brunei (1986), Vietnã (1995), Laos e Myanmar (1997) e Camboja (1999). Para maior histórico da ASEAN ver Ba (2009).
}

artigo pretende apresentar em linhas gerais, através de um estudo quali-quantitativo, a importância daquela região, bem como um panorama dos lados do conflito e suas reivindicações e ainda apresentar as razões para o Brasil ser um dos primeiros afetados por uma hipotética crise no MSC.

\section{O Mar do Sul da China e sua importância}

O MSC, tem uma importância estratégica que ultrapassa a questão regional. $E$, por tal razão, as disputas territoriais que se originaram no período da descolonização no pós-Segunda Guerra Mundial podem refletir tão profundamente na política global.

O MSC é um mar semi-fechado, sendo considerado pela Convenção das Nações Unidas sobre o Direito do Mar (UNCLOS no original) "uma bacia, golfo ou um mar cercado por dois ou mais Estados ligado a outro mar por um canal estreito" (ONU, 1982, UNCLOS parte IX, artigo 122, p. 63). São seis os Estados que circundam este mar, China (e Taiwan), Vietnã, Brunei, Malásia, Indonésia e Filipinas; o acesso a ele se dá a Sudoeste pelo estreito de Málaca e a Nordeste pelo estreito de Taiwan. Um dos alvos das disputas são dois grandes grupos de ilhas: as Ilhas Spratly, localizadas mais ao Sul, e Paracel, mais ao Norte. Além de outros pequenos atóis e recifes, a disputa também ocorre na região do Recife de Scarborough e das Ilhas Natuna, rica em campos de gás.

Esta configuração topográfica restringe a entrada de grandes embarcações, mas metade da tonelagem mundial, cerca de $90 \%$ dos bens transportados por navio e dois terços do suprimento de gás natural líquido consumido no mundo passam por essas duas rotas (CRONIN, 2012). O MSC abriga também campos de gás natural. Cerca de $80 \%$ do petróleo importado por Taiwan, Coréia do Sul e Japão também passa por suas rotas. Além disso, estudos apontam que o MSC possui cerca de 213 bilhões de barris de petróleo inexplorados em seu piso marítimo e 


\section{NEİBA}

se configura como a quarta maior origem pesqueira do mundo (THANG;THAO, 2012). Vale ressaltar ainda que o MSC liga o Oriente Médio ao Oceano Pacífico, o que Ihe agrega ainda maior estratégico.

Sendo assim, o MSC é disputado pelos Estados que o circundam. Contudo, não só estes Estados se inserem nos contentos territoriais. Por sua importância estratégica, grandes potências voltam sua atenção para o que está acontecendo na região. As características do MSC e o interesse que desperta nos países ao seu redor tornam a região um caldeirão propício para o conflito (KAPLAN, 2014).

\section{Os Conflitos no Mar do Sul da China}

A ASEAN, uma associação que metade de seus membros envolvidos reivindicações territoriais, está sendo amplamente questionada sobre o seu papel de pouco destaque nas disputas sobre o MSC (THAYER, 2012). A China por sua vez, busca neutralizar a ASEAN, com quem tem uma declaração apenas sugestiva sobre a conduta das partes na região contestada (Declaração de Conduta ou DOC) e, ao mesmo tempo, se esquivar das leis internacionais estabelecidas pela UNCLOS, ratificada também pelo Estado chinês. Os EUA, ator influente na região, observa de perto os atuais choques entre a China e os países menores e enxergam com preocupação as amplas reivindicações chinesas, que dariam a esse país controle quase total do espaço aéreo e marítimo da região.

As demandas dos países que estão localizados no MSC são geográficas, mas envolvem questões históricas, econômicas e consequentemente, de segurança e defesa. A constituição física e topográfica do MSC acirra as disputas territoriais, uma vez que as reivindicações de cada um dos países banhados pelo mar se sobrepõem (Figura 1).

Entretanto, nem todas as reivindicações feitas pelos países diretamente afetados por suas posições geográficas no MSC estão de acordo com o que a lei internacional indica como aceitável. A UNCLOS regula as reivindicações marítimas, estabelece parâmetros para a demanda por Mar Territorial, Zona Contígua, Zona Econômica Exclusiva (ZEE) e Plataforma Continental, além de indicar que tipo topográfico de ilha pode fazer reivindicações sobre o mar que a cerca. A Convenção, ratificada por todos os países que se encontram no MSC, mas não pelos EUA, aponta dois métodos para resolução de disputas em áreas sobrepostas: ajuste de reivindicações sem acionar a UNCLOS; e utilização do Tribunal Internacional do Direito do Mar, da Corte Internacional de Justiça ou de um tribunal especial (THANG;THAO, 2012).

As reivindicações territoriais no MSC não eram tão acirradas antes de 1973 quando passou-se a dar aos Estados o direito de reivindicar 200 milhas náuticas de ZEE a partir da costa de uma ilha ou conjunto de ilhas que fizesse parte de seu território (BECKMAN, 2014). Atualmente as reivindicações são feitas por Vietnã, Filipinas, Brunei, Malásia e Indonésia (em menor escala), membros da ASEAN, além de China (e Taiwan). Outros membros da ASEAN não possuem demandas no Mar do Sul da China, porque não se localizam neste mar, como Camboja, Laos, Myanmar e Tailândia além de Cingapura, que não tem demanda territorial sobre a região. por país. ${ }^{2}$

Figura 1 - O MSC e as reivindicações territoriais

\footnotetext{
2 Fonte:<www.southchinasea.org > Acesso em 17/02/2018
} 


\section{NEIBA}

VOLUME VII

Dossiê: SimpoRI 2018

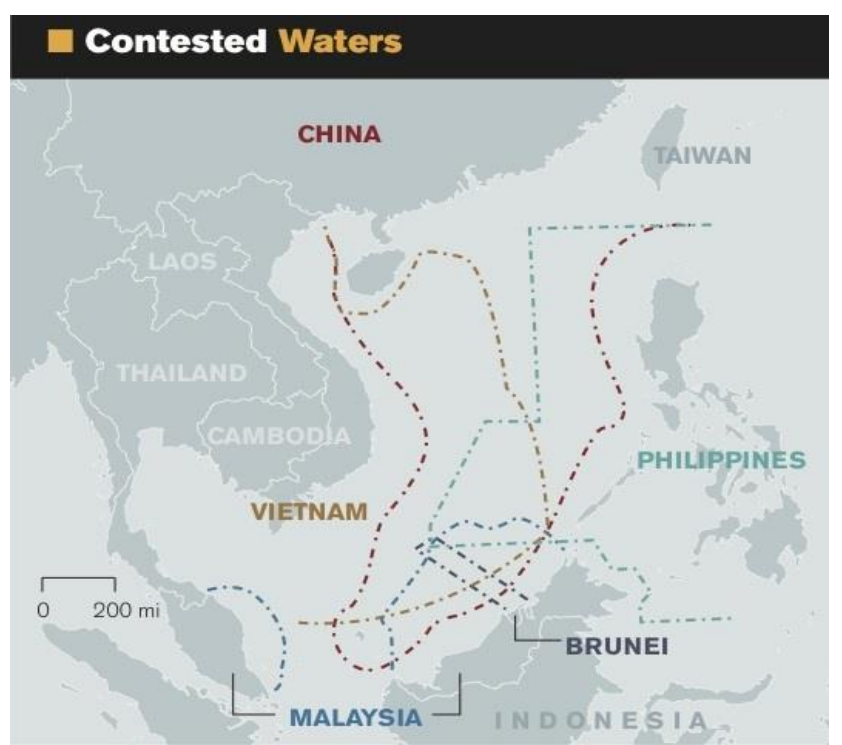

Figura 2 - Localização de ilhas, recifes e atóis no Mar do Sul da China ${ }^{3}$

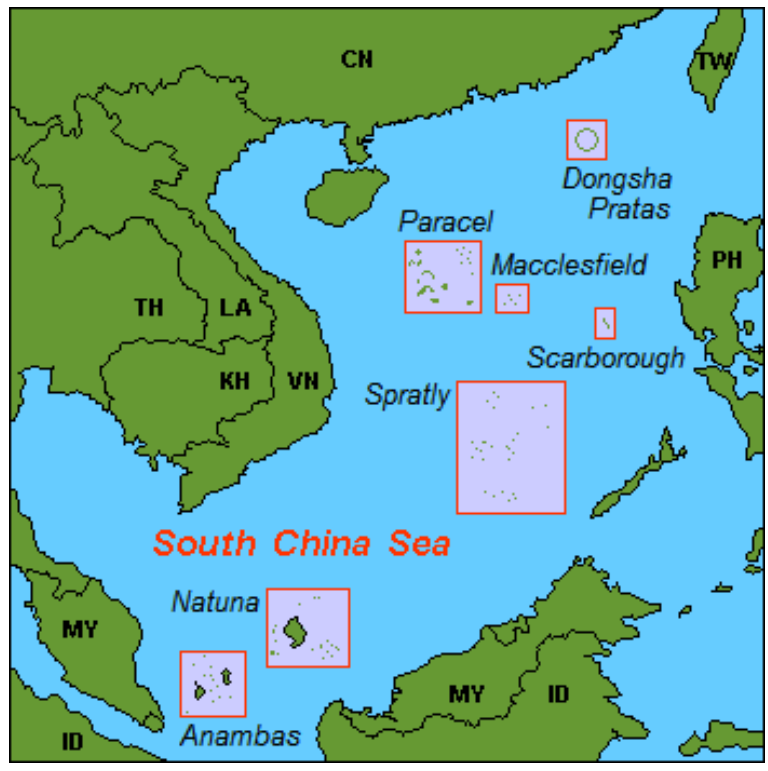

${ }^{3}$ Fonte: <http://www.chinadaily.com.cn/opinion/201106/28/content_12795760.htm> Acesso em 17/02/2018
O Estado chinês, principal ator da região, reivindica $0 \mathrm{MSC}$ em sua quase totalidade (Figura 1), cerca de 90\%, (NUDELMAN ET AL,2014) - a chamada Nine Dash Line - incluindo as Ilhas Paracel e Spratly além do Recife de Scarborough e as Ilhas Natuna. (Figura 2). A demanda chinesa ultrapassa as reivindicações legais estabelecidas pela UNCLOS para Mar Territorial. Outro ator que reivindica o MSC em sua quase totalidade é o Vietnã, incluindo as Ilhas Spratly e Paracel. O que diferencia a reivindicação vietnamita da chinesa, além da área, que no caso do Vietnã é um pouco menor, (Figura 1) é que o Vietnã reivindica a área como ZEE. As demandas territoriais do Estado filipino, mesmo ultrapassando o que a UNCLOS estipula como legal, se restringem a uma ZEE mais abrangente devido a busca pela expansão de sua indústria pesqueira. A presença de navios pesqueiros filipinos em áreas contestadas por China e Filipinas, também é fonte de parte da confrontação entre os países.

As reivindicações da ZEE feitas pela Malásia estão dentro do que a UNCLOS classifica como legal. Entretanto, o Estado malaio reivindica que as ilhas do conjunto Spratly, que estão dentro de sua ZEE, sejam consideradas território do país, que não consta na UNCLOS. Brunei e Indonésia também têm reivindicações no Mar do Sul da China. As demandas de ambos os países estão dentro do previsto pela UNCLOS e são exclusivamente para propósitos econômicos. Enquanto Brunei reivindica o atol Louisa, a Indonésia foca sua atenção na superposição da Nine Dash Line chinesa com os Campos de Gás das Ilhas Natuna, localizadas em parte de sua ZEE (Figura 2). (GOLDENZIEL, 2015)

Alguns embates contemporâneos ilustram as reivindicações territoriais no Mar do Sul da China. Recentemente, houve troca de farpas entre China e Filipinas quando um país acusava o outro de fortalecer sua presença militar nas Ilhas Spratly. No ano de 2012, o contento foi sobre as incursões no Recife Scarborough, que fica nas águas disputadas entre 


\section{NEİBA}

ambos os países, mas muito mais próximas das Filipinas (Figura 2). Em 2013 as Filipinas levam as disputas com a China para um tribunal internacional da UNCLOS, deixando de lado diversas resoluções do DOC, desagradando a China e enfraquecendo a ASEAN $^{4}$.

Ainda em 2012 a China criou um corpo administrativo com quartéis generais nas Ilhas Paracel, que gerou protestos não só nas Filipinas, mas também no Vietnã. (BBC ONLINE, 2014). Foi também com o Vietnã que a China travou outro tenso embate recente. O contento se iniciou em maio de 2014 devido a uma sonda de perfuração chinesa posicionada próxima as Ilhas Paracel, território contestado por ambos. O Vietnã exigiu a retirada das embarcações chinesas envolvidas na procura por petróleo e gás natural no que considera ser sua ZEE. A China, por sua vez, considera a região como parte de seu Mar Territorial. (HODAL, 2014).

As tensões no MSC vêm escalonando principalmente pelas reações de Estados Unidos aos avanços chineses sobre as Ilhas Spratly. Desde 2012, é possível perceber a maciça presença chinesas através de fotografias e vídeos de satélites comerciais. O país vem aterrando parte de pequenas ilhas, rochas e corais nas Ilhas Spratly e muitos entendem que esta nova ilha artificial que está sendo criada seja utilizada para propósitos militares (TIEZZI, 2015). A tensão não se resume apenas à construção de novas ilhas em águas contestadas, mas também a restrição da atuação norte americana na região.

Esta preocupação dos EUA tornou-se ainda mais clara com as recentes vigilâncias chinesas sobre

\footnotetext{
${ }^{4}$ Uma decisão final sobre o pleito filipino foi divulgada em 12 de julho de 2016 pela Corte Internacional de Justiça e o resultado foi majoritariamente favorável às Filipinas indicando abuso chinês em suas águas territoriais, deslegitimando o discurso chinês de direito histórico à região da Nine Dash Line, e se colocando contrária ainda à construção de ilhas artificiais por parte do Estado Chinês. Disponível em: <http://thediplomat.com/wpcontent/uploads/2016/07/thediplomat_2016-07-12_09-15-37.pdf>
}

os aviões norte-americanos ao passarem por áreas consideradas internacionais pelos EUA e chinesas pela Marinha chinesa (SCIUTTO, 2015). Também, em 2015, EUA, Japão e Austrália lançaram uma declaração conjunta expressando preocupação em relação à movimentação chinesa sobre áreas contestadas. (MISSILE THREAT, 2015)

\section{Por que os conflitos importam para o Brasil?}

Pouca é a atenção dada pela política externa brasileira durante todo o período republicano à Ásia, seja pela distância física ou por desconhecimento de ambos os lados no que diz respeito a uma relação mais profunda nos campos comerciais, de investimento ou imigração. À região asiática, considerada por diversos pensadores como a região mais dinâmica do planeta em termos de capitalismo (ARRIGHI, 1996, p370-371), fora destinada o segundo plano dos interesses políticos e econômicos do Brasil, uma vez que as prioridades sempre foram a potência norte-americana, os países europeus eos países vizinhos, nessa ordem; sendo o continente africano por diversas vezes mais importante que o asiático para os formuladores e executores da política externa brasileira. (MASIERO, 2007, p. 274)

Para Altemani(2005, p. 237), a relação brasileira com o Japão é entendida como inercial, com a Coréia do Sul incipiente e com o Sudeste Asiático praticamente inexistente. Mas o relacionamento brasileiro com a China demonstra um crescimento intenso e um estreitamento principalmente comercial e no que diz respeito às questões das relações Sul-Sul.

Desde a chegada dos anos 2000, houve considerável aumento não só do relacionamento entre Brasil e China, como também da importância dos dois Estados no Cenário Internacional. As relações entre os dois Estados de fato ganharam maior importância e volume nas últimas décadas, o que representa uma série de pontos positivos para ambos os países. Desde 2009, a China é o principal parceiro comercial do Brasil 


\section{NEIBA}

ultrapassando os EUA, que até então detinham esta posição. A partir de então, nossa pauta exportadora está cada vez mais ligada às necessidades asiáticas, principalmente chinesas, e tudo que acontece 'do outro lado do mundo' tem maior ou menor impacto no país.

Do comércio total brasileiro de 2007 até 2017, $78,39 \%$ são transportados por via marítima. O Brasil exporta cerca de 1/3 de sua produção total para o Leste Asiático ${ }^{5}$. Em 2017 foram 30,54\% segundo dados do MDIC (2018), e deste montante 87,45\%foram exportados através dos oceanos neste mesmo ano (MDIC, 2018). No que diz respeito a importação brasileira proveniente do Leste Asiático o montante total é de US\$ 43 bilhões no ano de 2017 e destes,73.86\% são transportados através do Mar. O Gráfico 1 apresenta o comércio total do Brasil com o Leste Asiático de 1997 a 2017, detalhando a quantidade de comércio via marítima (MDIC, 2018).

O Gráfico 2 apresenta o comércio total detalhado com os principais parceiros brasileiros no Leste Asiático, já os dados apresentados no Gráfico 3 detalham quanto do comércio total com cada um dos parceiros do Leste Asiático entre 1997 e 2017 foi feito por via marítima. $\mathrm{O}$ Gráfico 4 apresenta em percentual a flutuação do comércio total entre Brasil e Leste Asiático via mar. É possível perceber, a partir da análise dos quatro primeiros gráficos apresentados, não só a importância que a região tem para o comércio total brasileiro, mas também como este comércioé cada vez mais dependente das rotas marítimas.

Gráfico 1: Comércio Total do Brasil com o Leste Asiático e total do comércio marítimo (1997-2017) ${ }^{6}$

\footnotetext{
${ }^{5}$ Entendemos como Leste Asiático o conjunto de países que inclui: China, Japão, Coreia do Norte, Coreia do Sul e os 10 países que formam a ASEAN

${ }^{6}$ Fonte: <www.aliceweb.mdic.gov.br> Elaboração própria. Acesso em $17 / 02 / 2018$
}

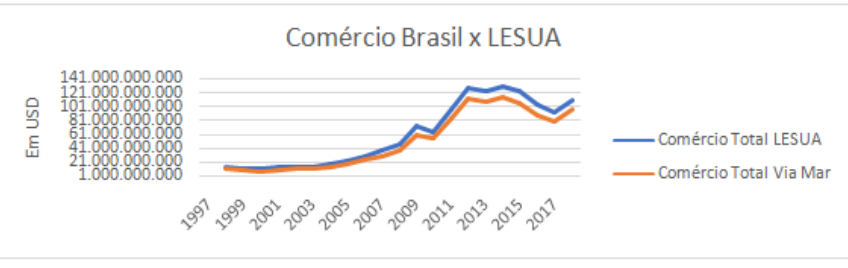

Gráfico 2: Comércio Total do Brasil com principais parceiros do Leste Asiático (1997-2017) ${ }^{7}$

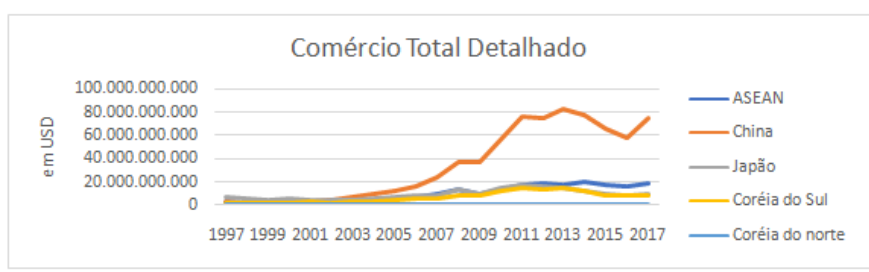

Gráfico 3: Percentual do comércio do Brasil para o Leste Asiático via mar (1997-2017) com parceiros detalhados $^{8}$

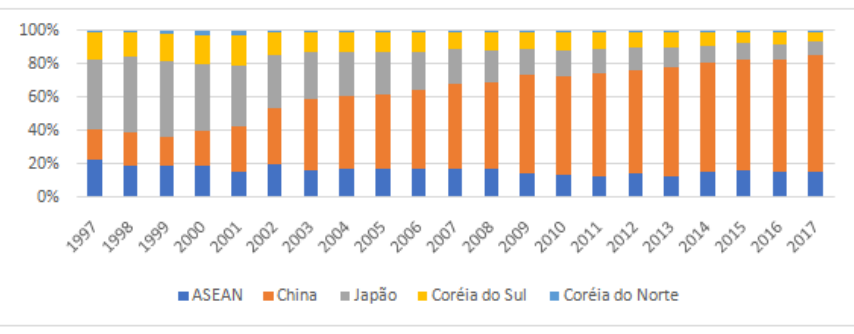

Gráfico 4: Flutuação do comércio total BrasilLeste Asiático por via marítima em percentual (1997$2017)^{9}$

\footnotetext{
${ }^{7}$ Fonte: <www.aliceweb.mdic.gov.br> Elaboração própria. Acesso em 17/02/2018

${ }^{8}$ Fonte: <www.aliceweb.mdic.gov.br> Elaboração própria. Acesso em 17/02/2018

${ }^{9}$ Fonte: <www.aliceweb.mdic.gov.br> Elaboração própria. Acesso em $17 / 02 / 2018$
} 


\section{NEİBA}

\section{8}

Percentual do Comércio Martítimo para o LESUA

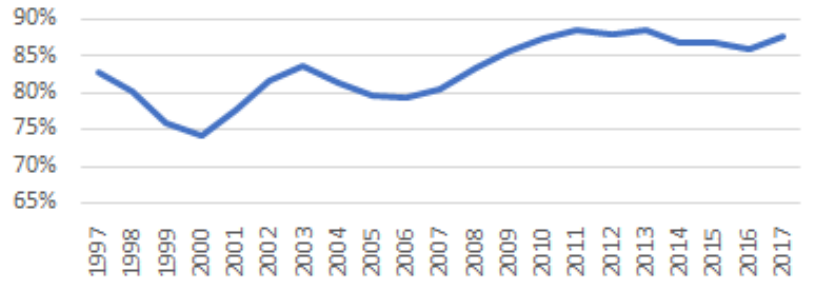

O Fórum Econômico Mundial aponta a rota marítima do MSC, com entrada através do Estreito de Málaca como a mais importante do mundo no que diz respeito ao comércio de petróleo bruto, com o transporte de milhões de barris por dia, como é possível perceber pela Figura 3 (HIRST, 2014). De todaexportação brasileira para Leste Asiático no ano de 2017,25 \% são de petróleo bruto(MDIC, 2018), e boa parte faz o mesmo caminho indicado pela Figura 3 . Em 2011 cerca de 1 milhão de barris de petróleo bruto chegaram para o Leste Asiático através do Estreito de Málaca, via MSC, de outras origens que não o Golfo Pérsico e a África (Figura 3). Mesmo sem estar claramente especificado na figura, o petróleo bruto do Brasil para a região está contido neste número. o $\mathrm{MSC}^{10}$

Figura 3: Principais rotas de petróleo bruto para

10 Fonte: < https://www.weforum.org/agenda/2014/05/world-mostimportant-trade-route/> acesso em 17/02/2018

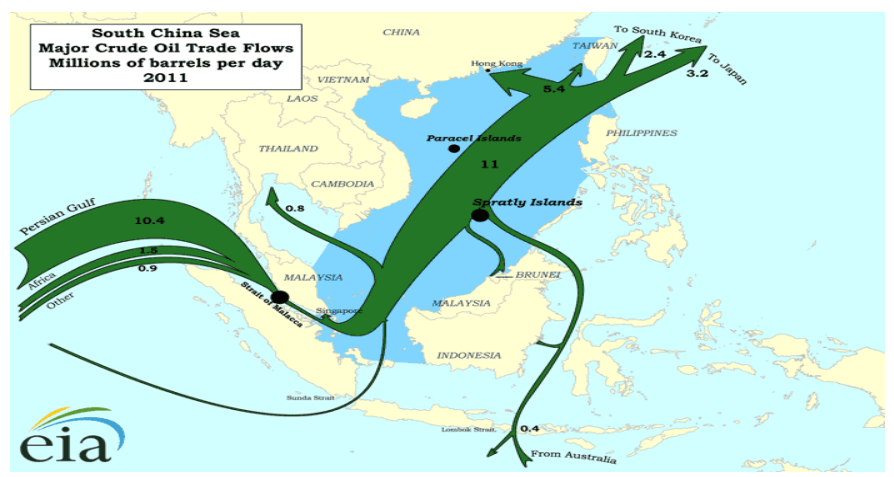

A Figura 4 apresenta as principais rotas comerciais marítimasmundiais para containers, e três delas saem do Brasil. Das três, ao menos duas, vão em direção ao Leste Asiático (uma via Canal de Suez e outra através do sul da África), acessado pelo Estreito de Málaca e em seguida pelo MSC.A outra vai em direção ao Atlântico, mais especificamente para a América do Norte e Europa Ocidental. Ao menos quatro das principais rotas comerciais passam pelo Estreito de Málaca e pelo MSC.

Figura 4: Principais rotas marítimas mundiais de transporte de containers ${ }^{11}$

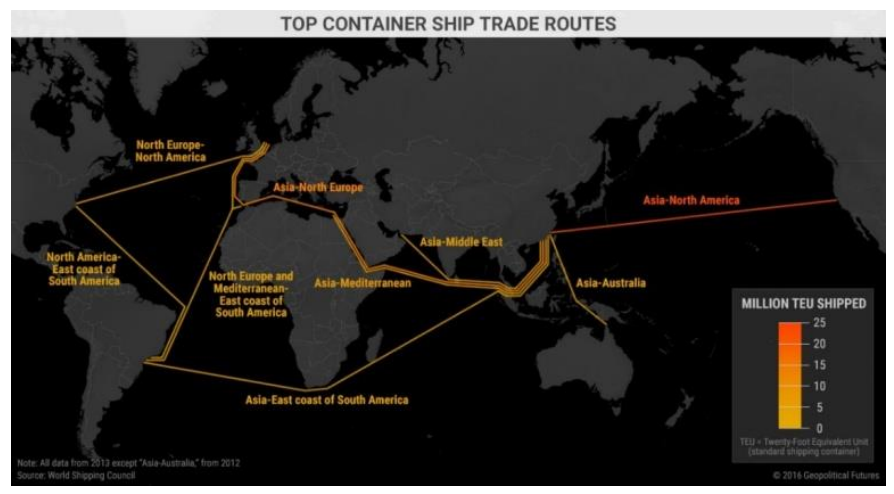

11 Fonte: < https://geopoliticalfutures.com/top-container-ship-traderoutes/> acesso em 17/02/2018 


\section{NEIBA}

VOLUME VII

2018

\section{Dossiê: SimpoRI 2018}

Desde 1997, segundo dados do MDIC (2018), o Brasil possui uma balança comercia superavitária com o Leste Asiático, como apresenta o Gráfico 5. Um conflito de médias proporções entre grandes potências como Estados Unidos e China, ou até mesmo entre China e alguns dos países do Sudeste Asiático pode afetar diretamente o comércio brasileiro, uma vez que mais de $30 \%$ do total das exportações do país são dedicadas a região do Leste Asiático. Asiático ${ }^{12}$

Gráfico 5: Balança Comercial Brasil e Leste 20.000.000.000

Poucas são as rotas alternativas para manter 0 fluxo comercial para o Leste Asiático. A Figura 5 apresenta as rotas primarias e secundárias de comércio e os principais pontos de atenção - o Estreito de Málaca merece atenção especial também neste mapa. Até mesmo uma possível rota alternativa para alcançar o Leste Asiático via Canal do Panamá, precisaria passar pelo Estreito de Taiwan - também uma área de conflitos - que levaria novamente a parte mais norte do MSC.

Figura 5: Principais rotas comerciais marítimas ${ }^{13}$

\footnotetext{
12 Fonte: <www.aliceweb.mdic.gov.br> Elaboração própria. Acesso em 17/02/2018

${ }^{13}$ Fonte: <

https://people.hofstra.edu/geotrans/eng/gallery/Map_Main\%20Maritime $\% 20$ Routes.pdf> Acesso em 17/02/2018
}

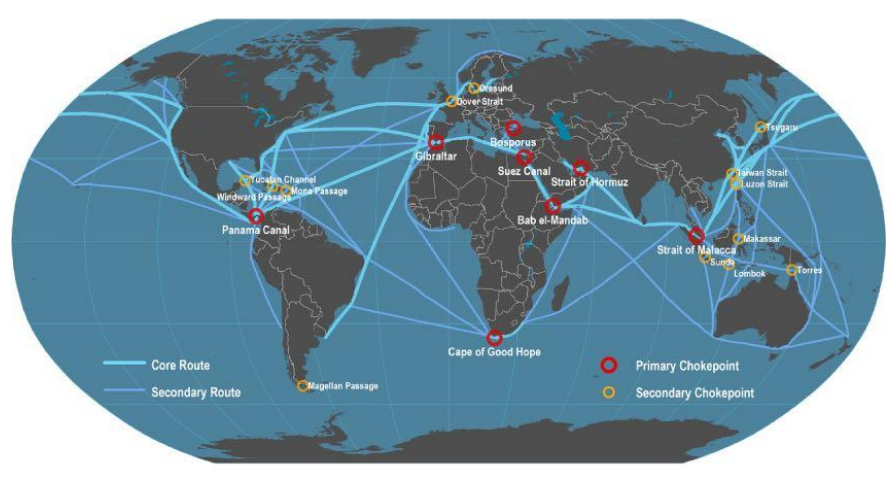

Uma alternativa pouco viável para o comércio entre Brasil e Leste Asiático evitando um possível conflito de médias proporções no MSC seria o transporte das mercadorias via ar. O problema desta modalidade é o limite, bem mais reduzido, da tonelagem e o preço considerando a distância e capacidade de cada aeronave.Esta solução provavelmente encareceria o custo das mercadorias e poderia afetar diretamente boa parte das exportações do país não só para o se principal parceiro comercial, a China, como para toda uma região que recebe uma grande parte das nossas exportações.

Manter o comércio por via marítima, buscando rotas alternativas, que também podem encarecer as mercadorias, traria o mesmo resultado preocupante para as exportações brasileiras e a balança comercial do país com o mundo, podendo desencadear um período de crises internas por um fator externo e praticamente desconhecido por boa parte da população.

\section{Considerações Finais}

O principal objetivo deste artigo foi trazer informações sobre um assunto pouco conhecido e debatido pelos grandes veículos de comunicação do país, e até mesmo pela academia e pelo governo. Sobre Ásia, há uma limitação muito clara sobre o interesse brasileiro na China principalmente pelo alto fluxo comercial e pelas parcerias e acordos estratégicos 


\section{NEIBA}

VOLUME VII

Dossiê: SimpoRI 2018

feitos entre os dois atores bilateralmente e em fóruns internacionais. Contudo, há grande desconhecimento sobre a política chinesa e os diversos conflitos nos quais o país se envolve.

Sobre os conflitos no MSC, há ainda menos conhecimento, mesmo sendo um assunto sensível para - Brasil, cada vez mais ligado ao comércio com seus parceiros asiáticos e tão dependente, como boa parte do mundo, desta rota marítima. Através dos mapas e gráficos apresentados, esperamos que o artigo seja um incentivo para que haja maior interesse na região do MSC uma vez que, mesmo sendo 'do outro lado do mundo', está cada vez mais próximo a realidade brasileira. Buscar alternativas com antecedência - como maior diversificação de parceiros ou estudospara uma nova rota marítima - para se preparar para uma possível dificuldade futura nas rotas comerciais, é o melhor caminho para prevenir crises futuras para o país. 


\section{NEIBA}

VOLUME VII

Dossiê: SimpoRI 2018

\section{8}

\section{BIBLIOGRAFIA}

ALTEMANI, Henrique.(2005) Política Externa Brasileira . São Paulo: Saraiva.

ARRIGHI, Giovanni.(1996) O Longo Século XX. dinheiro, poder e as origens de nosso tempo. Rio de Janeiro:

Contraponto.

BBC ONLINE (2014) "Q\&A: South China Sea dispute" BBC Online.8 de maio.. Disponível em:

<http://www.bbc.com/news/world-asia-pacific-13748349> [Acesso em:04/09/2018]

BECKMAN, Robert. (2014) "ASEAN and the South China Sea Dispute". In CHAVHAVALPONGPUN, Pavin. "Entering Uncharted Waters? ASEAN and the South China Sea". ISEAS Publising: Singapore.

CHINA DAILY. (2011) China's claim on South China Sea 'indisputable'. Disponível em:

<http://www.chinadaily.com.cn/opinion/2011-06/28/content_12795760.htm>[Acesso em:04/09/2018]

CORTE INTERNACIONAL DE JUSTIÇA. (2016) "The South China Sea Arbitration - Press Released. 12 de julhoDisponivel em: <http://thediplomat.com/wp-content/uploads/2016/07/thediplomat_2016-07-12_09-15-37.pdf>[Acesso em:09/09/2018]

CRONIN, Patrick.(2012) "Cooperation from Strength: The United States, China and the South China Sea" Center for a New American Security.Janeiro.

GEOPOLITICAL FUTURE.(2016)Top Container Ship Trade Routes. 16 de dezembro Disponível em: < https://geopoliticalfutures.com/top-container-ship-trade-routes/> [Acesso em:18/08/2018]

GOLDENZIEL, Jill.(2015) "International Law Is the Real Threat to China's South China Sea Claims". The Diplomat Online, 03 de novembro. Disponivel em: <http://thediplomat.com/2015/11/international-law-is-the-real-threat-to-chinas-southchina-sea-claims/> [Acesso em:20/08/2018]

HIRST, Tomas.(2014)The world's most importante trade route?World EconomicForum. 21 de maio. Disponível em: < https://www.weforum.org/agenda/2014/05/world-most-important-trade-route/> [Acesso em:05/09/2018]

HODAL, Kate. (2014) "Despite oil rig removal, China and Vietnam row still simmers" The Guardian Online, 17 de julho. Disponível em: <http://www.theguardian.com/world/2014/jul/17/oil-rig-china-vietnam-row-south-china-sea>[Acesso em:05/09/2018]

KAPLAN, Robert D.(2014) "Asia's Cauldron: the South China Sea and the end of a stable Pacific". New York: RandomHouse.

MASIERO, Gilmar.(2007) Negócios como Japão, Coréia do Sul e China:Economia, gestão e relações com o Brasil. São Paulo: Saraiva. 


\section{NEIBA}

MINISTERIO DA INDÚSTRIA, COMÉRCIO EXTERIOR E SERVIÇOS (MDIC) (2018) - Alice Web.

Disponívelem<http://aliceweb.mdic.gov.br/>.[Acesso em:22/08/2018]

MISSILE THREAT.(2015) "Japan, U.S., Australia air concern over South China Sea / China urged to exercise selfrestraint on reclamation". MissileThreat Online. 31 de maio Disponivel em: <http://missilethreat.com/japan-u-s-australiaair-concern-over-south-china-sea-china-urged-to-exercise-self-restraint-on-reclamation/> [Acesso em:02/09/2018]

NUDELMAN, Mike; ROSEN,ARMIN; KELLEY, Michael. (2014)"This Map Shows Why The South China Sea Could Lead To The Next World War". Business Insider, 10 de julho. Disponivel em: <http://www.businessinsider.com/the-south-chinasea-graphic-2014-7>[Acesso em:22/08/2018]

RODRIGUES, Jean-Paul.(2017)Main Maritime Shipping Routes. Department of Global Studies and Geography - Hofstra University. Disponível em: <https://people.hofstra.edu/geotrans/eng/gallery/Map_Main\%20Maritime\%20Routes.pdf> [Acesso em:28/08/2018]

SCIUTTO, Jim. (2015) "Exclusive: China warns U.S. surveillance plane”. CNN Online, 27 de maio. Disponível em: <http://edition.cnn.com/2015/05/20/politics/south-china-sea-navy-flight/index.html> [Acesso em:18/08/2018]

THANG, Nguyen-Dand;THAO, Nguyen Hong.(2012)“China's nine dotted lines in the South China Sea: the 2011 exchange of diplomatic notes between the Philippines and China" In Ocean Development and International Law, vol. $43 \mathrm{n}$ 1 (Jan-Mar 2012).Disponível em: <https://www.tandfonline.com/doi/abs/10.1080/00908320.2012.647490>[Acesso em:04/09/2018]

THAYER, Carlyle. "ASEAN'S Code of Conduct in the South China Sea: A Litmus Test for Community-Building?," The Asia-Pacific Journal, Vol 10, Issue 34, No. 4, August 20, 2012.Disponível em: <http://www.japanfocus.org/-carlyle_A_Thayer/3813>[Acesso em:04/09/2018]

THE SOUTH CHINA SEA: An online resource for students, scholars and policy-makers interested in development, environment and security issues.(2018)Disponivelem: <http://www.southchinasea.org>[Acesso em:02/09/2018]

TIEZZI, Shannon. (2015) Revealed: China's Reasons for Island-Building in the South China Sea. The Diplomat Online. 10 de abril. Disponível em:<http://thediplomat.com/2015/04/revealed-chinas-reasons-for-island-building-in-the-south-chinaseal>[Acesso em:20/08/2018]

UNCLOS - ONU. CONVENÇÃO DAS NAÇÕES UNIDAS SOBRE O DIREITO DO MAR, (1982). Disponível em: $<h t t p: / / w w w . u n . o r g / d e p t s / l o s / c o n v e n t i o n \_a g r e e m e n t s / t e x t s / u n c l o s / c l o s i n d x . h t m>$ [Acesso em: 12/08/2018]

ZHIYUE, Bo.(2015) "Could the South China Sea Cause a China-US Military Conflict?" in: The Diplomat Online.27 de maio. Disponivel em: < https://thediplomat.com/2015/05/could-the-south-china-sea-cause-a-china-us-military-conflict/>. [Acesso em:04/09/2018]

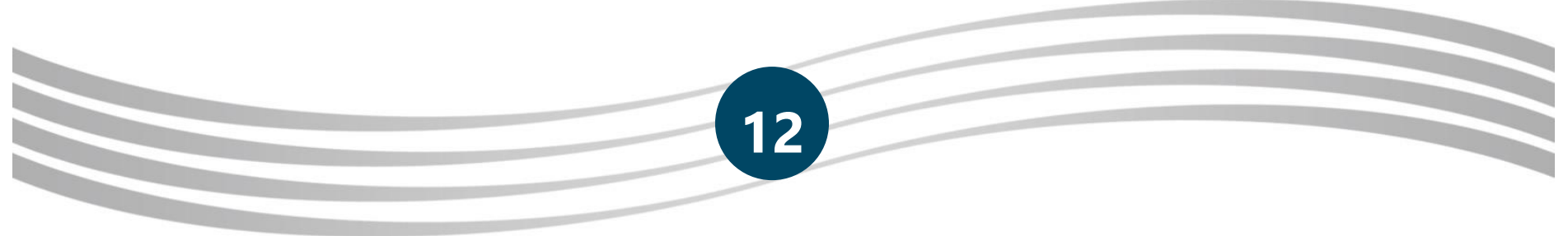

